
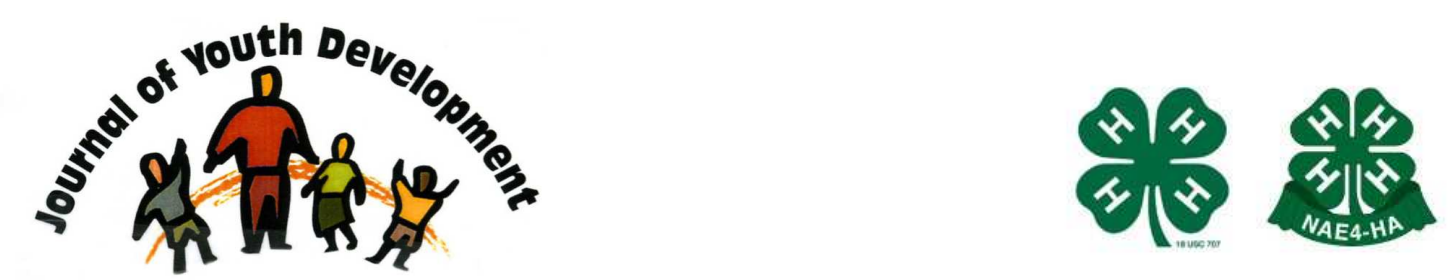

Bridging Research \& Practice

\title{
Program Innovations and Character in Cub Scouts: Findings from Year 1 of a Mixed-Methods, Longitudinal Study
}

\author{
Lacey J. Hilliard \\ Tufts University \\ Medford, MA \\ lacey.hilliard@tufts.edu \\ Rachel M. Hershberg \\ Tufts University \\ Medford, MA \\ Jun Wang \\ Tufts University \\ Medford, MA \\ Edmond P. Bowers \\ Clemson University \\ Clemson, SC \\ Paul A. Chase \\ Tufts University \\ Medford, MA \\ Robey B. Champine \\ Tufts University \\ Medford, MA \\ Mary H. Buckingham \\ Tufts University \\ Medford, MA \\ Daniel J. A. Warren \\ Tufts University \\ Medford, MA \\ Kaitlyn A. Ferris
}


West Virginia University

Morgantown, WV

Richard M. Lerner

Tufts University

Medford, MA 


\section{Program Innovations and Character in Cub Scouts: Findings from Year 1 of a Mixed-Methods, Longitudinal Study}

Lacey J. Hilliard, Rachel M. Hershberg, Jun Wang, Paul A. Chase, Robey B. Champine, Mary H. Buckingham, Daniel J.A. Warren and Richard M. Lerner

Tufts University

Edmond P. Bowers

Clemson University

Kaitlyn A. Ferris

West Virginia University

Abstract: Youth development programs seek to promote positive development through mentoring and engaging youth in opportunities for individual growth and community connectedness. We present findings from the initial phase of a mixed-methods, longitudinal study aimed at assessing the impact of one such program, Cub Scouts, on character development. We assessed if Scouting, and a recent innovation in Scouting focused on program quality, are associated with the development of character and other positive youth outcomes. Participants were 1,083 Scouts and nonScouts, aged 5-12 years. At the start of the study, there was no difference in indicators of character between Scouts and non-Scouts, once matched through propensity score analyses. Through content analyses of interviews and short-answer questionnaires administered to leaders, we found that leaders' views of character and of their roles corresponded to those envisioned by Cub Scouts. Implications for character development, and for the role of program components in character development, are discussed. 


\section{Introduction}

The mission of major youth development programs is to develop positive attributes in young people (e.g., character virtues, prosocial behaviors, and positive civic actions; e.g., Eccles, \& Gootman, 2002; Sherrod, Flanagan, \& Torney-Purta, 2010; Vandell, Larson, Mahoney, \& Watts, in press). The vision of these programs is aligned with the positive youth development (PYD) model of adolescent development (e.g., Damon, 2004; Larson, 2000; Lerner, Lerner, Bowers, \& Geldhof, in press). The PYD perspective is a strength-based approach, derived from relational developmental systems (RDS) theories, models that use dynamic, systems concepts to represent mutually influential relations between individuals. The perspective includes the multiple (biological through cultural, physical, and historical) and integrated levels of organization within the ecology of human development (Overton, 2013a, 2013b, in press). The PYD perspective is one RDS-based model, and it posits that positive development emerges when the strengths of young people (e.g., intentional self-regulation skills; Gestsdottir, \& Lerner, 2008) are aligned with key ecological developmental assets (i.e., supports in their environments, such as parental warmth, monitoring, and engagement and community-based, organized out-of-school time [OST] activities; Lerner et al., 2005; Vandell, et al., in press). For instance, OST youth development programs that promote a PYD perspective are designed to be safe spaces that:

1. provide youth with extensive opportunities for sustained, caring and supportive relationships with adults;

2. promote the development of life-skills through program activities; and

3. provide opportunities to contribute to, and assume a leadership role in, valued family, school, or community activities (Lerner, 2004).

Scouting constitutes an exemplar of such a program. The programs of the Boy Scouts of America (BSA) aim to imbue youth with the life skills needed to thrive personally and to develop into adults of character and responsible citizens who contribute positively to American democracy. In other words, the goal of BSA programs is to enable youth to live honorably as people and to do their duties as citizens. Despite these important goals of BSA programs, across the organization's more than 100-year history there has been little research that systematically or longitudinally investigates the impact of BSA programs on outcomes of youth involved in Scouting. The ability to conduct such longitudinal research in collaboration with major youth development programs, such as BSA, is challenging in light of continuous changes in program leadership, structure, and content. Furthermore, research efforts need to take into account social challenges related to program sustainability; for instance, challenges associated with participant recruitment or retention, expanding into new geographical areas, or engaging groups of youth who may have been underserved (Eccles, \& Gootman, 2002; Mahoney, et al., 2009; Vandell, et al., in press). For instance, BSA recently created a new professional position, known as the Quality Unit Executive (QUE), to focus on improving the quality of programs and to enhance recruitment and retention of participants. As part of efforts to engage youth from diverse socioeconomic backgrounds, BSA also implemented a program called ScoutReach, which has been designed to engage traditionally underserved populations (specifically youth of color and youth from low-income backgrounds) in Scouting.

Although community-based OST programs, such as BSA, continue to be regarded by researchers as key ecological assets involved in promoting PYD (e.g., Benson, et al., 2011; Vandell, et al., in press), such assets are "moving targets" in the actual ecology of youth development, given that they are always in the process of changing to improve their services 
and to address new challenges to program sustainability. As such, it is crucial that longitudinal research be conducted that is sensitive to the changing nature of this ecological asset. Such research is necessary in order to accurately gauge the effects of these programs on youth development. Accordingly, the current article presents an initial description of a longitudinal study that has been designed to assess the impact of the BSA program and its leadership model on youth development, but does so by including an assessment of program innovations (specifically, in the current article, of the impact of the QUE on program quality and outcomes). In subsequent reports from the present data set, we will also discuss the development of youth participating in the ScoutReach program, which, as noted, is another recent innovation of BSA programs.

The present article, then, constitutes an initial step in pursuing the overall goal of the research we are conducting with BSA youth; that is, to assess the impact of the BSA programs on indicators of youth character. Our research has focused on the beginning level of BSA programs Cub Scouts, which includes youth in first- through fifth-grade. At this level, Scouts are guided through the program by adult volunteers, with the explicit goal that, by the final level of the Cub Scouts program, youth will have gained sufficient autonomy in goal-seeking abilities and in leadership skills to aid them in succeeding progressively through the upper Boy Scout ranks (ideally, to attain the level of Eagle Scout) and, outside of Scouting, to live lives of honor and contribution in their local and global communities. In essence, then, the goal of BSA programs is to promote several domains of character (Lerner, \& Callina, in press; Lickona, \& Davidson, 2005; Seider, 2012): moral virtues (e.g., courage, honesty, fairness), performance character (e.g., attributes such as initiative, diligence, perseverance), and civic character (e.g., attributes such as social skills and social knowledge that enable responsible and engaged citizenship).

Current scholarship in the study of character development adopts this multidimensional conception of the content and structure of character that underlies the activities and curriculum of BSA programs (e.g., Lickona, \& Davidson, 2005; Seider, 2012; Shields, 2011). However, current conceptualizations of the bases of character development adopt a RDS approach (e.g., Lapsley, \& Narvaez, 2006; Lerner, \& Callina, in press; Sokol, Hammond, \& Berkowitz, 2010), and emphasize that character develops through mutually beneficial relationships between an individual and his or her contexts. This literature also notes that there is a relative absence of information about the role of specific individual-context relations in promoting the character development of youth, especially during childhood and early adolescence and in regard to OST settings (e.g., Lerner, \& Callina, in press). Because community-based OST youth programs constitute an important context for positive developmental attributes, such as the domains of character of interest within BSA programs (e.g., Lerner, et al., in press; Vandell, et al., in press), the present article is useful and timely.

Scouting seeks to promote character attributes through engaging youth in skill-building activities and providing them with opportunities to apply these skills in different contexts (e.g., at camp or in other outdoor settings). BSA also strives to ensure that its programs are delivered with fidelity and quality across Scout packs, troops, and councils (levels of increasing participant aggregation in BSA, i.e., packs are embedded within troops, and troops are embedded within councils). Accordingly, the research we are undertaking seeks to describe the course of character development among youth participating in Cub Scout programs and, as well, to describe whether an innovation of BSA program delivery (i.e., the use of a new program professional, known as the QUE) is effective in enhancing the delivery of BSA programs at the level of packs and troops. Scout packs are led by adult volunteers (typically parents of participants), and the role of the QUE is designed to oversee and help these volunteer leaders 
deliver BSA programs with quality and fidelity. In short, the ultimate goal of the QUE is to enhance the success of BSA programs by improving the quality and fidelity with which pack leaders deliver the Scouting program to Scouts.

There is some prior research that has attempted to examine the impact of Scouting on the prosocial behaviors and positive development of youth who participate in Scouting (Harris Interactive, 2003; Jang, Johnson, \& Kim, 2012; Louis Harris \& Associates, 1998; Polson, Kim, Jang, Johnson, \& Smith, 2013). The findings of this research suggest that BSA programs help to enhance character development, well-being, values, social relationships, decision-making skills, and goal achievement among Scouts, as compared to youth not involved in Scouting. However, this research is largely non-developmental and, as such, lacks information about the specific processes through which components of the BSA program (e.g., leader-Scout interactions, BSA curriculum, or BSA activities, such as camping, outdoor recreation, etc.) influence specific developmental outcomes among Scouts.

Accordingly, in order to provide these descriptions, we have conducted a study that uses both quantitative and qualitative methods to assess multiple dimensions of the BSA program. We gathered data from Cub Scouts, adult volunteer leaders, and professional staff. The project which we have labeled the Character and Merit Project (CAMP) - will include four waves of quantitative data (across three years) collected from youth involved in Scouting and, in an effort to account for the effects of endogeneity, from a propensity-score-matched group of youth who are not involved in Scouting. As discussed later in this article, in forming these matched groups we used demographic data (e.g., age) as well as measures linked to the assessment of PYD (e.g., academic performance) in order to assess potential character differences between BSA participants and non-participants. In addition, qualitative data were collected through interviews with QUEs and through short-answer questionnaires circulated to adult volunteers serving as pack leaders.

In sum, the present article is intended to serve as a foundational report about the CAMP study. As such, we present the overall design of the study, describe our quantitative and qualitative methods, and present initial findings from the first wave of data collection. These analyses addressed the following three questions:

1. What features of character do youth possess at their entry into the Cub Scout program, and do these attributes differ from those of youth who are not participating in Cub Scouts?;

2. How do QUEs and pack leaders describe their roles and experiences in Cub Scouting, and in regard to the innovation of the QUE program in particular?; and

3. Are leaders' descriptions of their roles and experiences commensurate with BSA program goals in regard to character development?

\section{Method}

\section{The Research Context}

The Character and Merit Project (CAMP) is being conducted within the greater Philadelphia area. The BSA Council within this region is the Cradle of Liberty (COL) Council. The COL initiates its programs following the national mission of BSA programs throughout the U.S. The COL serves 10,000 Scouts, and is facilitated by volunteer leaders (mostly Cub Scout parents) from 250 packs throughout the region. In addition, the COL includes various professional staff members who provide support to volunteer leaders throughout the region. As we have noted, a new innovation in staff support to volunteers and their packs is the Quality Unit Executive 
(QUE). The key mission of QUEs is to enhance the probability that pack leaders will deliver BSA programs (i.e., curriculum/activities) to Scouts with fidelity. Other components of the QUE position included serving as a coach to pack leaders, teaching leaders to increase parent involvement, ensuring leaders complete training, and helping packs with scheduling, budgets, and communication. The personnel in the QUE role were hired to act as personal coaches, counselors, and support systems for the volunteer leaders. The goal of the QUE innovation is to enhance program quality and improve recruitment and retention of participants and, in turn, enhance the character outcomes envisioned by BSA. In the COL, eight QUEs were hired to support pack leaders in eight of the 12 districts in the Council.

\section{Participants}

This sample at the first wave of testing was comprised of 1,083 boys between 5 and 12 years of age $(M=8.85, S D=1.39)$. There were 915 Cub Scout participants, with 407 boys ( $44.4 \%)$ embedded in QUE-serving Cub Scout packs and 508 boys embedded in non-QUE-serving Cub Scout packs. In addition, we collected data from 168 boys who did not participate in Cub Scouts. Participants were: $76.6 \%$ White or European American; $13.1 \%$ Black or African American; $4.6 \%$ Hispanic or Latino; .8\% Multiethnic or Multiracial; $2.3 \%$ Asian or Pacific Islander; .2\% American Indian; and $2.4 \%$ did not provide this information. Detailed demographic information about Scout and non-Scout participants can be found in Table 1. 
Table 1

Demographic Information about Scout and non-Scout Participants

\begin{tabular}{|c|c|c|c|c|c|c|c|}
\hline & & \multicolumn{2}{|c|}{ Scouts } & \multicolumn{2}{|c|}{ non-Scouts } & \multicolumn{2}{|c|}{ Total } \\
\hline & & Count & $\%$ in group & Count & $\%$ in group & Count & $\%$ \\
\hline \multirow[t]{7}{*}{$\begin{array}{l}\text { Race } \\
\text { /ethnicity }\end{array}$} & $\begin{array}{l}\text { American } \\
\text { Indian/Native } \\
\text { American }\end{array}$ & 0 & .00 & 2 & 1.30 & 2 & .20 \\
\hline & $\begin{array}{l}\text { Asian or Pacific } \\
\text { Islander }\end{array}$ & 18 & 2.20 & 4 & 2.50 & 22 & 2.30 \\
\hline & $\begin{array}{l}\text { Black or African } \\
\text { American }\end{array}$ & 84 & 10.50 & 42 & 26.60 & 126 & 13.10 \\
\hline & $\begin{array}{l}\text { Hispanic or } \\
\text { Latino/Latina }\end{array}$ & 33 & 4.10 & 11 & 7.00 & 44 & 4.60 \\
\hline & White & 643 & 80.10 & 93 & 58.90 & 736 & 76.60 \\
\hline & $\begin{array}{l}\text { Multiethnic or } \\
\text { multiracial }\end{array}$ & 2 & .20 & 6 & 3.80 & 8 & .80 \\
\hline & Other & 23 & 2.90 & 0 & .00 & 23 & 2.40 \\
\hline \multirow{13}{*}{$\begin{array}{l}\text { Tapestry Score } \\
\text { based on pack } \\
\text { or school } \\
\text { address }\end{array}$} & 3 & 43 & 4.70 & 0 & .00 & 43 & 4.00 \\
\hline & 4 & 25 & 2.80 & 0 & .00 & 25 & 2.30 \\
\hline & 5 & 62 & 6.80 & 0 & .00 & 62 & 5.70 \\
\hline & 6 & 15 & 1.70 & 0 & .00 & 15 & 1.40 \\
\hline & 9 & 36 & 4.00 & 0 & .00 & 36 & 3.30 \\
\hline & 13 & 261 & 28.70 & 0 & .00 & 261 & 24.10 \\
\hline & 14 & 32 & 3.50 & 0 & .00 & 32 & 3.00 \\
\hline & 18 & 89 & 9.80 & 0 & .00 & 89 & 8.20 \\
\hline & 24 & 67 & 7.40 & 0 & .00 & 67 & 6.20 \\
\hline & 29 & 0 & .00 & 44 & 25.10 & 44 & 4.10 \\
\hline & 30 & 13 & 1.40 & 0 & .00 & 13 & 1.20 \\
\hline & 32 & 41 & 4.50 & 57 & 32.60 & 98 & 9.00 \\
\hline & 54 & 224 & 24.70 & 74 & 42.30 & 298 & 27.50 \\
\hline \multirow{2}{*}{$\begin{array}{l}\text { Institutional } \\
\text { Religiosity }\end{array}$} & non-religious & 246 & 27.30 & 75 & 43.00 & 321 & 29.80 \\
\hline & religious & 656 & 72.70 & 100 & 57.00 & 756 & 70.20 \\
\hline
\end{tabular}

As shown in the table, there are some demographic differences between the Scout and the non-Scout groups. For example, although most participants in both groups were White or European American, the percentage in the initial sampling is much greater in the Scouts $(80.1 \%)$ than in the non-Scout $(58.9 \%)$ participants. The non-Scout group had a greater proportion of Black or African American participants (26.6\%) than the Scout group (10.5\%). As Scout participants were recruited from more districts than the non-Scout participants, tapestry scores of the Scouts demonstrated more variability than those of non-Scout participants. A greater percentage of Scouts $(72.7 \%)$ were recruited from religious institutions than non-Scouts (57\%). However, Scouts' presence in churches for weekly pack meetings is quite different from non-Scouts' presence in Catholic schools for daily school activities. As explained below, any selection effects associated with differences in participants' backgrounds were controlled through the use of propensity scores. To gauge the potential impact of QUEs on packs, we solicited the participation of pack leaders who either did or did not work in QUE districts. A total 
of 107 pack leaders (of whom, 38\% worked with a QUE) completed a short-answer questionnaire with 11 open-ended items.

\section{Measures}

We used both quantitative and qualitative measures during the first wave of testing. To identify what features of character youth have at their entry into the Cub Scout program, and if these attributes differed from those of youth not participating in Cub Scouts, we administered the Assessment of Character in Children and Early Adolescents (ACCEA) measure (Wang, et al., 2014) to Scouts and non-Scouts. Qualitative measures included the QUE semi-structured interview protocol and the open-ended questions on the pack leader short-answer questionnaire. The interview protocol was designed to elicit QUE's descriptions and understandings of their roles in Scouting and in relation to working with packs. We conducted the QUE interviews during the first wave of testing in order to be able to assess QUE'S understanding of their positions in BSA programs at the start of the study and therefore prior to assessing longitudinally the potential QUE impact on Scout outcomes.

The pack leader short-answer questionnaire was designed to gain more information about pack leaders' experiences in Scouting and with QUEs. We also used the pack leader questionnaires to assess leaders' views of Scouting and of character development through Scouting. It was important to garner information about the pack leader experience, as the leaders are the link between QUEs and Scouts, and because it is through the QUEs' relationships and work with pack leaders that pack leaders are expected to deliver a high quality program to Scouts.

Assessment of Character in Childhood and Early Adolescence (ACCEA). As part of the CAMP project, we developed the ACCEA (Wang, et al., 2014) to assess seven character attributes derived from the Boy Scout Oath (obedience - operationalized as rule-following; reverence - operationalized as religiosity; cheerfulness; kindness; thriftiness; trustworthiness; and helpfulness) and one attribute (hopeful future expectations), associated with the PYD literature (Schmid, \& Lopez, 2011). A study of the character strengths of a large sample of U.S. adults (McGrath, 2014), using the Values in Action Inventory of Strengths (Peterson, \& Seligman, 2004), found that Future Orientation is a key character attribute which is characterized by a positive outlook, hopefulness, and an interest in healthy living. The response scale for each item in ACCEA was 1 to 5, where 1 indicated "Not at all like me" and 5 indicated "Exactly like me." Wang, et al. (2014) also studied Cub Scouts from the COL and, specifically, assessed the factorial structure of the ACCEA. They found a first-order model consisting of eight correlated factors, a second-order model consisting of one superordinate character factor and eight first-order factors, and a bifactor model consisting of one general character factor and eight specific character attributes. All models were theoretically plausible and fit the data well. Therefore, depending on the focus of the study, the ACCEA can be used to measure each of the eight individual character attributes as well as the general construct of character. In the current study, subscale scores of each of the eight character attributes measured by ACCEA were used to explore the character attributes of our sample. Cronbach's alphas for the whole sample were .66 for rule-following (four items), .75 for religiosity (four items), .78 for cheerfulness (three items), .82 for kindness (four items), .60 for thriftiness (four items), .81 for trustworthiness (five items), .81 for helpfulness (five items), and .71 for hopeful future expectation (three items). These coefficients did not vary appreciably or systematically across the Scout and nonScout groups.

Background Control Variables. Youth age, race/ethnicity, school tapestry segmentation, institutional religiosity, and youth self-rated academic performance were collected from the 
parents and the organizations (Scout packs or schools) to control for potential demographic difference between Scouts and non-Scouts. As noted these data are summarized in Table 1. The Tapestry Segmentation is associated with the neighborhoods in which the packs or schools of all participating youth are located (ESRI, 2012). Based on data sources (e.g., Census, 2000, 2010), Tapestry Segmentation classified United States neighborhoods into 65 distinct segments by using several measures that distinguish critical characteristics of the residents, such as income, family type, education, and employment. Tapestry scores may range from 1 to 65 , with higher scores for a district indicating better living situations, income, and housing. Institutional religiosity was a binary variable representing the religious versus non-religious nature of the institution from which our participants were recruited (e.g., church versus community center for pack meetings, Catholic versus regular school for comparison group participants). Youth selfrated academic performance was measured using five items from the academic competence subscale of the Self-Perception Profile for Children (SPPC; Harter, 1982, 1983), such as "I am very good at my schoolwork" and "I like to learn new things." Cronbach's alpha for this variable in the present dataset was .67.

QUE Interviews. In order to understand how individual QUEs understood their roles at the start of this study and, specifically, their roles in relation to pack leaders and Scouts, we developed a semi-structured interview protocol with the COL based on the specification of the QUE role (described above). The QUE interview protocol included questions about the QUE role in relation to BSA programs, in relation to pack leaders, and in relation to Scout outcomes. The protocol also included open-ended questions about the importance of BSA to the U.S. and the world, and about how QUEs understood their role in relation to the overall mission of BSA programs. To protect the identities of QUEs in this study, we do not provide any identifying information about the QUEs when we present findings from our analyses of their interviews.

Pack Leader Short-Answer Questionnaire. We used the online Qualtrics program to develop a pack leader short-answer questionnaire containing 10 background items, 12 QUEspecific items, and 11 open-ended items. We circulated this questionnaire throughout the COL with the hope of recruiting pack leaders for participation in this study who had a variety of experiences with and histories in Scouting. Items on the short-answer questionnaire, therefore, specifically inquired about leaders' backgrounds in Scouting, motivations for becoming Scout leaders and their interactions with QUES. Open-ended questions were also included, and these items aimed to elicit leaders' understandings of the QUE innovation, definitions of character, and their views of how they and BSA programs influence character development in Scouts. We included these character-related questions because we believed it was essential to gauge leaders' views of character and their role in its development at the start of the study (and before assessing character development longitudinally). Pack leaders have the most direct contact with Scouts and, presumably, the most influence over the positive outcomes they may foster through exposure to BSA programs and activities. Through this questionnaire, we could potentially ascertain, for example, if pack leaders adhere to the character program that BSA intends for them to deliver to Scouts. If we were to learn that these leaders did not adopt the character development goals of BSA programs, than we would be aware of potential challenges to accurately identifying and assessing the processes through which QUEs and pack leaders influence character development in the context of Scouting.

\section{Procedure}

To recruit participants, we asked adult leaders of Cub Scout packs to help make parents aware of the study, collect parental consent, and administer the questionnaires during pack meetings. In addition, we contacted pack leaders from across the COL to aid in recruiting, with the aim of 
having half of the participants be from QUE districts. In turn, we recruited a comparison sample of youth who are not in Scouting but who are from similar socio-demographic backgrounds as the Scouts in this sample. Schools within the greater Pennsylvania area surrounding Philadelphia were contacted, and we were able to involve nine public, charter, and/or Catholic schools that included youth in Grades 1-5. Within each school, students in all first through fifth grade classes were invited to participate. The youth we included in our comparison sample did not participate in any Cub Scout programs.

To obtain parental consent for Scouts, pack leaders gave each child an envelope to take home to his parent or guardian. The envelope contained a letter that described the study and provided researchers' contact information if parents had questions or concerns. It also included a parent consent form, a parent questionnaire (PQ), and a plain letter envelope in which to return the parent questionnaire and consent form to the pack. The information requested in the PQ included family background information and data regarding youth activity participation (in addition to Scouting). When Scout packs reported experiencing difficulties in getting paperwork to and from parents, we provided self-addressed stamped envelopes. To thank pack leaders for participating in the data collection process, we provided each pack with a $\$ 50$ gift card. Each Scout received a $\$ 20$ gift card upon completion of the questionnaire. Questionnaire materials were administered by pack leaders, who followed a detailed protocol. Most participants were able to complete the survey within 15 minutes.

Interviews with the eight QUEs were conducted in the COL offices. Interviews were between 30 minutes to one hour in length. Seven of the interviews were audio-recorded; one interviewee preferred responses to be typed but not audio-recorded. The interviews were transcribed by members of the research team prior to being analyzed and interview transcripts were checked for errors and corrected accordingly. Links to the online pack leader questionnaires were circulated to leaders throughout the COL at several points during the study. Data were downloaded into an Excel file from Qualtrics for review and analyses.

\section{Plan of Analysis}

The goal of the larger CAMP study is to integrate longitudinal quantitative and qualitative analyses of data in order to examine if and how attributes of character develop in Scouts. We will also examine if specific program innovations, such as the QUE program, influence the development of character in Cub Scouts. In the present analyses, we used the quantitative and qualitative data collected at the first wave of testing to address the three previously-noted questions.

Quantitative data were used exclusively to answer our first research question: What features of character do youth possess at their entry into the Cub Scout program, and do these attributes differ from those of youth who are not participating in Cub Scouts? We specifically conducted analyses of baseline quantitative data collected from Scouts and non-Scouts using the ACCEA measure (Wang, et al., 2014). Qualitative analyses, drawing from QUE interviews and pack leader responses to the open-ended items on the short-answer questionnaire, were used to address the second research question: How do QUEs and pack leaders describe their roles and experiences in Cub Scouting (and in particular, in regard to the innovation of the QUE program)? Qualitative analyses conducted to address this question focused on QUE interview data pertinent to QUEs' descriptions of their understandings of their roles in Cub Scouts and in regard to working with pack leaders and influencing experiences of Scouts in the program. These analyses also examined pack leaders' responses to an open-ended item about their experiences with QUEs. 
Qualitative analyses of the pack leader short-answer questionnaire were also conducted to address the third research question: Are leaders' descriptions of their roles and experiences commensurate with BSA program goals in regard to character development; that is, in regard to putting youth on a life path of honor and duty? To address this question, we specifically focused on pack leaders' responses to open-ended items regarding their

1. Definitions of character development, and

2. Understandings of if and how they influenced character development.

Analysis Plan for Quantitative Youth Data. We present a comparison of ACCEA scores for the Scout and the non-Scout participants. We first make this comparison without statistical control and then with statistical control in order to account for the possible effects of endogeneity. In the latter comparison, we use propensity scores as a covariate to overcome possible selection effects in our data set (Rosenbaum, \& Rubin, 1985). The use of propensity scores has been advocated as an effective approach for addressing concerns of nonequivalent groups in research and for making causal inferences when youth were not randomly assigned to a program versus a non-program group (Harder, Stuart, \& Anthony, 2010; Heckman, Ichimura, Smith \& Todd, 1997, 1998). Background variables which might influence participation in BSA and character attributes were used to create propensity scores, including youth age, race/ethnicity, school tapestry segmentation, institutional religiosity, and youth self-rated academic performance.

Analysis Plan for Qualitative Data. In order to identify the main topics discussed across the eight QUE interviews, two members of our team implemented a content coding procedure of the interview data (Hsieh, \& Shannon, 2005). We followed the same procedure with responses from pack leaders to three of the open-ended items on the short-answer questionnaire: "Please describe your understanding of the QUE role," "How do you define character?," and "Do you try to influence the development of character in Scouts? Please explain." The coding procedure involved two of the authors independently assigning descriptive codes to the data and coming together to discuss these codes (Saldaña, 2012). Through discussion, we refined codes until we came to $100 \%$ agreement about which codes best represented the range of responses provided by leaders.

After applying codes to the responses from each individual leader, we calculated the percentage of responses that we identified under each code to aid in specifying the salience of particular codes. As Sandelowski notes (2001), calculating percentages in this way can allow for the identification of patterns in a data set, and lead to the development of new questions. After coding and analyzing the data, we examined our findings in relation to BSA program goals, to assess whether the multiple descriptions that QUEs and pack leaders provided of their Scouting and character-related experiences in BSA programs were reflective of the descriptions provided by BSA programs of the COL.

\section{Results}

The purpose of this study was to describe indicators of character in Scouts and non-Scouts, and to describe how QUEs and pack leaders understand their roles in Scouting and in relation to developing character in Scouts. We explored three research questions to bring data to bear on these aims of the study. We present results from our first wave of the study organized by these three research questions. 


\section{Results for Research Question 1}

Question 1 asked if character attributes of Cub Scouts differ from those of non-Cub Scout youth. Before presenting the results of the analyses that we conduced to address this question, we present descriptive statistics for each ACCEA scale, including the means and standard deviations for the Scouts and non-Scout participants. These data are presented in Table 2. Bivariate correlations among the scales are also presented in the table. The data presented in the table indicate that most of the character attributes correlated with each other at moderate levels, and that the values were comparable across the Scout and non-Scout groups.

Table 2

Descriptive Statistics for the Assessment of Character in Children and Early Adolescents (ACCEA) Attributes in Scouts and non-Scouts

\begin{tabular}{|c|c|c|c|c|c|c|c|c|c|c|}
\hline ACCEA Attributes & 1 & 2 & 3 & 4 & 5 & 6 & 7 & 8 & Mean & $S D$ \\
\hline 1. Obedience & -- & $.18^{*}$ & $.28^{*}$ & $.48^{*}$ & $.40^{*}$ & $.35^{*}$ & $.50^{*}$ & $.37^{*}$ & 3.99 & .74 \\
\hline 2. Reverence & 15 & -- & $.27^{*}$ & $.30^{*}$ & $.31^{*}$ & $.30^{*}$ & $.26^{*}$ & $.33^{*}$ & 3.79 & 1.01 \\
\hline 3. Cheerfulness & $.39^{*}$ & $.41^{*}$ & -- & $.50^{*}$ & $.28^{*}$ & $.45^{*}$ & $.34^{*}$ & $.47^{*}$ & 4.08 & .88 \\
\hline 4. Kindness & $.49^{*}$ & $.32^{*}$ & $.54^{*}$ & -- & $.47^{*}$ & $.51^{*}$ & $.58^{*}$ & $.69^{*}$ & 4.31 & .73 \\
\hline 5. Thriftiness & $.46^{*}$ & $.40^{*}$ & $.42^{*}$ & $.49^{*}$ & -- & $.36^{*}$ & $.48^{*}$ & $.51^{*}$ & 3.82 & .82 \\
\hline $\begin{array}{l}\text { 6. Hopeful future } \\
\text { expectation }\end{array}$ & $.39^{*}$ & $.41^{*}$ & $.51^{*}$ & $.54^{*}$ & $.49^{*}$ & -- & $.47^{*}$ & $.50^{*}$ & 4.51 & .63 \\
\hline 7. Trustworthiness & $.65^{*}$ & $.32^{*}$ & $.51^{*}$ & $.60^{*}$ & $.54^{*}$ & $.50^{*}$ & -- & $.63^{*}$ & 4.14 & .74 \\
\hline 8. Helpfulness & $.34^{*}$ & $.33^{*}$ & $.53^{*}$ & $.64^{*}$ & $.44^{*}$ & $.53^{*}$ & $.55^{*}$ & -- & 4.10 & .74 \\
\hline Overall Mean & 4.08 & $\begin{array}{l}4.2 \\
1\end{array}$ & $\begin{array}{l}3.9 \\
9\end{array}$ & $\begin{array}{l}4.2 \\
2\end{array}$ & $\begin{array}{l}3.8 \\
7\end{array}$ & $\begin{array}{l}4.5 \\
3\end{array}$ & $\begin{array}{l}4.1 \\
5\end{array}$ & $\begin{array}{l}4.1 \\
4\end{array}$ & -- & -- \\
\hline Overall $S D$ & .69 & .84 & .89 & .71 & .80 & .65 & .70 & .71 & -- & -- \\
\hline \multicolumn{11}{|c|}{$\begin{array}{l}\text { Note. Scout participants }(N=895) \text { are above the diagonal and non-Scout participants }(N= \\
168) \text { are below the diagonal. } \\
{ }^{*} p<.01 .\end{array}$} \\
\hline
\end{tabular}

To address Question 1, we conducted two one-way between group, fixed effects multivariate analyses of variances (MANOVAs), with the between dimension being Scout versus non-Scout participation and the dependent variables being the vector of scores of the eight character scales included in the ACCEA measure. One MANOVA involved the non-propensity-scored data for the participants. However, the second MANOVA involved the use of propensity scores for the participants as a covariate (and hence this analysis was actually a MANCOVA). In the first MANOVA, a significant main effect was obtained for BSA status, $F(8,987)=7.65, p<.001$, 
partial $\eta^{2}=.06$. Follow-up univariate analyses of variance for this main effect indicated significant between-group differences for one of the eight attributes tested, reverence; for this difference, non-Scouts had higher scores, $F(1,994)=34.23, p<.001$, partial $\eta^{2}=.03$. All other composite scales showed no significant between-group differences.

In the second, MANCOVA analysis, which adjusted for potential selection bias between Scouts and non-Scouts, the main effect for BSA status disappeared when the propensity score was simultaneously entered as a covariate. No significant differences in character attributes remained between Scout and non-Scout participants. As such, the difference in reverence in the first analysis may have been due to the presence of many Catholic school students in the comparison group. The second analysis controlled for potential demographic differences in youth age, race/ethnicity, institutional religiosity, and tapestry scores, as well as academic competence scores. No character difference between the Scout and non-Scout participants was found in the project's first wave of data. This finding is useful as it allows unbiased (by endogeneity) comparative assessment of (1) the potential differential association between Scout participation versus non-Scout participation, and (2) youth character development in future waves of the CAMP study.

\section{Results for Research Question 2}

Question 2 asked how QUEs and pack leaders describe their roles and experiences in Cub Scouting, as well as their understanding of the QUE innovation. To answer this question, we conducted content analyses of both the QUE interviews and the open-ended item on the shortanswer questionnaire regarding pack leaders' understandings of the QUE. We first examined analyses of the QUE interview data to assess how QUEs describe their understandings of their roles in BSA programs at the start of the study, and whether these understandings were commensurate with BSA program goals. We then examined findings from our analyses of one of the open-ended questions on the pack leader short-answer questionnaire, to assess if the understandings of pack leaders, who are reportedly being served by a QUE, also reflect BSA program goals regarding the QUEs' interactions with pack leaders.

In our content analysis of the QUE interview data, we identified 10 main codes that reflected various components of the QUE data. However, only some of these codes fit with each of the eight interviews. The codes that were most prominent in our analysis reflected the main goals for the QUE position, as described by BSA Programs of the COL. As illustrated below, all eight QUEs described their roles as involving:

1. Serving as a coach to the pack leaders with whom they worked and, thus, offering support in some way;

2. Ensuring pack leaders were trained; and,

3. Coordinating recruitment of Scouts.

Several other aspects of the QUE position were reported by some (but not all) of the QUEs. These reports helped to further illustrate the ways in which QUEs understood their roles and responsibilities within BSA programs and, specifically, in regard to working with pack leaders (see Table 3). Accordingly, we provide several excerpts from these QUE interviews to highlight the main components of the QUE roles that were discussed across interviews, and to elucidate the potential ways in which QUEs may effect change within BSA programs. 
Table 3

Codes Applied to Quality Unit Executive (QUE) Interview Responses about Definitions and Purpose of the QUE Role

\begin{tabular}{|l|c|}
\hline Code & $\begin{array}{c}\text { N (\% of total } \\
\text { respondents) }\end{array}$ \\
\hline Serving as personal coach and counselor to pack leaders & $8(100 \%)$ \\
\hline Ensuring pack leaders were trained & $8(100 \%)$ \\
\hline Coordinating recruitment of Scouts & $8(100 \%)$ \\
\hline Teaching pack leaders strategies for increasing parent involvement & $7(88 \%)$ \\
\hline Retaining Scouts in program & $7(88 \%)$ \\
\hline Working with pack leaders to organize calendars & $5(63 \%)$ \\
\hline Working with pack leaders to organize budgets & $5(63 \%)$ \\
\hline Working with pack leaders to organize popcorn sales & $5(63 \%)$ \\
\hline Orienting pack leaders to the advancement program & $4(50 \%)$ \\
\hline Impacting character development & $4(50 \%)$ \\
\hline
\end{tabular}

In describing his or her understanding of what the position of a QUE entailed, one QUE noted: I am the program person. I'm the person that comes in and helps you, the Cub Scout leader, with running your program and making sure that you have that good program and making sure we have a budget for you...the right fundraising so that you can afford to do all the great events that you want to take your kids to do...camping, and make sure everyone is trained so that they know how to run the right program.

In this excerpt, the QUE acknowledges that, in addition to helping packs run better, his or her role includes imparting knowledge and training to pack leaders around managing the budget, fundraising, and camping. In addition, this QUE articulated that he or she understood that helping leaders to be more successful fundraisers supports the larger objective of making Scouting more fun for youth, as more money means that packs can afford and plan "great events" for participants. Thus, this QUE described some of the main facets of his or her position within Scouting, and suggested how QUEs indirectly affect the experiences of Scouts whose packs are served by these staff.

Similarly, another QUE who was interviewed explained that the purpose of the QUE position was to make Scouting fun and to help packs perform at their best at all times. This QUE explained that his or her role consisted of:

[Making] sure that they're doing the program, they're making it fun, they're engaging the kids. Umm make sure they're putting their best foot forward at all times... I I guess my role right now is pretty much monitor the different Cub packs in the schools and make sure they're giving the kids the best possible program. 
In addition to identifying the technical components of the QUE position in relation to training pack leaders (i.e., ensuring leaders are sticking to or "doing the program" and engaging Scouts to the best of their abilities), this QUE also connected his or her roles and responsibilities to program outcomes and Scout experiences. In the beginning of this excerpt, for example, the QUE stated that his or her job is about making sure leaders "make it fun." This QUE also saw his or her responsibilities as having indirect effects on Scouts' experiences in BSA programs.

In contrast, a QUE who had less experience in Scouting said this about the QUE role: "My understanding of the position is as a support role of the existing Cub Scout packs [because] I focus more with the Cub Scouts. So to support the existing ones as well as to get new packs started. "This QUE may have not been aware of as many facets of the QUE position as were mentioned in the other QUE interviews because he/she was less experienced in the postion. In addition, unlike in the other excerpts, this QUE did not connect his or her role with packs to Scout outcomes. Nevertheless, this QUE was clear that he or she understood that some of the objectives of the QUE position are to support Cub Scout packs and help leaders initiate new packs. Thus, this QUE's articulations of some of the main QUE components also reflected the QUE role as described by the COL.

In sum, our analyses of QUE interviews suggested that, at Year 1, the "support" component of the QUE position was understood by all QUEs in this study, regardless of their experiences with, and histories in, Scouting. Moreover, QUEs generally understood that the support they were providing to packs had the aim of indirectly influencing character and other positive developmental outcomes in Scouts by enabling leaders to provide a more enjoyable and all around "better" program to Scouts. Such experiences could motivate Scouts to stay in Scouting for a longer period of time. These findings suggest that, although the eight QUEs were not aware of every facet of their position at the start of the study, they had some shared understanding that their QUE position was created because pack leaders, who are almost exclusively parents and volunteers, needed scaffolding and guidance as they set out to run BSA meetings and lead and grow their packs throughout the Scouting year.

Pack-leaders' experiences with QUES. In addition to assessing understandings of the QUE role through QUE interviews, and, thus, from the perspectives of QUEs themselves, the shortanswer questionnaires circulated to pack leaders throughout the COL also included questions about their views of the QUE position. Specifically, of the 107 pack leaders who completed the short-answer questionnaires, 41 identified their packs as being served by a QUE and responded to questions that attempted to gauge their knowledge of and experiences with QUEs. In their responses, most of these 41 leaders described receiving direct support from QUEs, and many articulated the various forms of support they received. In our analyses, we specifically identified 10 descriptive codes that captured the range of responses pack leaders provided to the question about the role of the QUE. As presented in Table 4, almost all of the pack leaders who identified being served by a QUE shared that their QUE was there to provide a form of general support or assistance. 


\section{Table 4}

Codes and Examples of Adult Volunteer Open-ended Responses about the Role of the Quality Unit Executive (QUE) Position. Leaders Responded to the Prompt: "Please describe your understanding of the QUE's role"

\begin{tabular}{|l|l|c|}
\hline Code & Example & $\begin{array}{l}\text { N (\% of total } \\
\text { respondents) }\end{array}$ \\
\hline Provide general support & "To assist the pack in whatever is needed" & $31(76 \%)$ \\
\hline $\begin{array}{l}\text { Help units deliver } \\
\text { quality program }\end{array}$ & $\begin{array}{l}\text { "Makes sure pack has every resources it needs to bring a } \\
\text { quality program to the boys" }\end{array}$ & $18(44 \%)$ \\
\hline $\begin{array}{l}\text { Assist with pack } \\
\text { advancement }\end{array}$ & $\begin{array}{l}\text { "The QUE's role is to provide the pack with knowledge, } \\
\text { resources and encouragement to improve the pack's } \\
\text { overall performance which is measured by the Journey to } \\
\text { Excellence scores." }\end{array}$ & $10(24 \%)$ \\
\hline $\begin{array}{l}\text { Assist with recruitment/ } \\
\text { retention }\end{array}$ & "Assist us with recruiting..." & $7(17 \%)$ \\
\hline $\begin{array}{l}\text { Ensure program is } \\
\text { delivered with fidelity }\end{array}$ & $\begin{array}{l}\text { "Make sure the units are delivering a program consistent } \\
\text { with the plan of BSA" }\end{array}$ & $6(15 \%)$ \\
\hline $\begin{array}{l}\text { Liaise between packs } \\
\text { and council }\end{array}$ & "Liaison with BSA through the local Council office" & $4(10 \%)$ \\
\hline Unsure of QUE role & $\begin{array}{l}\text { "I am not sure what the role of our QUE is yet. The QUE is } \\
\text { newly appointed." }\end{array}$ & $4(10 \%)$ \\
\hline $\begin{array}{l}\text { QUE unable to do } \\
\text { prescribed role }\end{array}$ & $\begin{array}{l}\text { "Unfortunately, our QUE at times gets pulled in to support } \\
\text { the District Executive role, taking away time that he } \\
\text { should be spending in his QUE role." }\end{array}$ & $1(2 \%)$ \\
\hline $\begin{array}{l}\text { Strengths of person } \\
\text { makes for great QUE }\end{array}$ & & $1(2 \%)$ \\
\hline Promote camping & $2(5 \%)$ \\
\hline
\end{tabular}

Specifically, 31 of the 41 pack leaders echoed the eight QUEs' responses, describing that the purpose of the QUE position is to provide support to the pack units. In turn, 18 of the 41 pack leaders who responded to the question specifically identified that the QUEs who served their packs were there to help them deliver a quality program to the Scouts. Several of these same leaders $(n=6)$ described that "quality program" means a program that also comports with the values of scouting and maintains fidelity to the Scouting program.

For example, one pack leader explained: "This person is there to make sure that the pack or unit is following the rules and understands how to put the Scout values in place when teaching the Scouts." Other leaders $(n=10)$ described a quality program, and the QUE's role in making a program higher quality, in terms of how well the pack as a whole was doing at advancing Scouts from one level of scouting to the next. For instance, one leader explained that the QUE role functions "to provide services to the pack so we may achieve 'Gold' on our 'Journey to Excellence' and, thus, run an awesome program." 
Several leaders also described the practical facets of the QUE role in terms of helping pack leaders recruit and retain families $(n=7)$, or helping packs promote summer camp $(n=2)$. For example, similar to findings from the QUE interviews, more pack leaders identified the QUE position as related to recruitment and retention of families, compared to promotion of summer camp. These parallel findings suggest that QUEs show individual differences in the implementation of their position (e.g., attending more to retention of Scouts versus popcorn sales or fundraising) and in their dynamics with pack leaders, which could have differential impacts on the leaders and, in turn, on Scouts.

\section{Results for Research Question 3.}

Question 3 asked if leaders' descriptions of their roles and experiences were commensurate with BSA program goals, with a specific focus on perceptions about character development in Scouts. Accordingly, and in addition to identifying how pack leaders understand the role of the QUE, we analyzed responses to short-answer questionnaires to ascertain pack leaders' definitions of character and their views of how they influenced character in Scouting. As presented in Table 5, through our coding and analysis, we created seven main codes that captured various dimensions in the definitions of character provided by pack leaders. We also found that several of these dimensions of character co-occurred in their responses. This finding enabled us to understand some of the complexity involved in how pack leaders understood character and how they aimed to influence its development.

\section{Table 5}

Codes and Examples of Adult Volunteer Open-ended Responses about Character. Leaders Responded to the Prompt: "How do you define character?"

\begin{tabular}{|l|l|c|}
\hline Code & Example & $\begin{array}{c}\text { N (\% of total } \\
\text { respondents) }\end{array}$ \\
\hline Dictates social actions & $\begin{array}{l}\text { "Character is how one conducts themselves in daily } \\
\text { life. The choices one makes and how one deals with } \\
\text { their interactions with others define one's } \\
\text { character." }\end{array}$ & $32(35 \%)$ \\
\hline Belief \& value systems & $\begin{array}{l}\text { "Character to me is how you present yourself. The } \\
\text { values you hold true to yourself and demonstrate in } \\
\text { your everyday life." }\end{array}$ & $31(34 \%)$ \\
\hline $\begin{array}{l}\text { Personal attributes/ } \\
\text { "It makes you who you }\end{array}$ & $\begin{array}{l}\text { "The sum of a person's attributes, traits, and } \\
\text { abilities, all of the things that make you who you } \\
\text { are." }\end{array}$ & $27(29 \%)$ \\
\hline Doing the right thing & "Doing the right thing, when no one is looking." & $17(19 \%)$ \\
\hline $\begin{array}{l}\text { How you interact with } \\
\text { others }\end{array}$ & $\begin{array}{l}\text { "Character is what makes a person stand out. How } \\
\text { they relate to others shows us their character. It is } \\
\text { the qualities that allow them to relate and interact } \\
\text { with adults and children." }\end{array}$ & $8(9 \%)$ \\
\hline Integrity & $\begin{array}{l}\text { "Integrity. Doing what you say you'll do, even when } \\
\text { no one is watching. Sticking to your beliefs even } \\
\text { when it is hard." }\end{array}$ & $6(7 \%)$ \\
\hline Scout Law \& Oath & "By the twelve points of the scout law." & $2(2 \%)$ \\
\hline
\end{tabular}


As shown in Table 5, the definitions of character provided by leaders also complemented the components of character that we sought to measure with the creation of our ACCEA measure (Wang, et al., 2014). The findings shown in the tabled suggested that the pack leaders adhered to BSA program goals. Several pack leaders, for example, explicitly defined character in terms of an attribute included in the Scout law (e.g., "I define character as someone, who is responsible, reliable and trustworthy"). Two leaders specifically reported defining character "by the 12 points of the Scout law."

One dimension of character that was most frequently reflected across pack leaders' definitions was that character is what determines one's actions toward settings and/or other people. For example, one leader noted that: "Character is how one conducts themselves in daily life. The choices one makes and how one deals with their interactions with others define one's character. "Other leaders focused explicitly on character as the basis for one's behaviors. One leader noted, for example, that character is: "How you act and behave, either on a routine basis or when extraordinary situations arise. "Another leader explained that character is simply: "The way one presents him/herself in public."

Although character was described as dictating extrinsic behaviors and social interactions (with people or settings) in approximately one-third of responses from leaders, nearly the same proportion of responses (31\%) included references to character as related to intrinsic processes, such as beliefs and values. One leader noted, for example, that character is "a person's mental, moral and ethical qualities. " In this response, the leader's understanding of character was that it is based on internal thoughts and/or values. Another leader explained that character is "core beliefs that define one's reactions to any given question, situation, or circumstance. "Although this leader also mentioned "beliefs" in his or her definition of character, references to external processes (i.e., reactions to questions, situations, or circumstances) were also present.

In our review of codes, we identified this co-occurrence of dimensions in several more responses from leaders. This finding led us to re-examine responses that we coded as "beliefs and value systems," as well as the responses coded as "dictates social actions." Through careful reexamination of responses from leaders, we identified that this co-occurrence of dimensions was present in the majority of responses from leaders.

In most of their responses to the question of "How do you define character?," leaders provided definitions of character as involving both intrinsic and extrinsic processes. Leaders defined character in terms of beliefs and values but, specifically, in terms of beliefs and values that determine or influence behaviors and actions toward settings and other people. One leader noted, for example, that: "Character is who and what we are on the inside-our inner most thoughts that determine our actions, decisions, and deeds. It is what we do when we think no one is looking. "In this excerpt, we can see that this leader defined character as involving what one thinks, feels, and does. This leader also explained that the result of this fusion of intrinsic and extrinsic features of a person is "what you do when no one is looking," another code we attached to many of the responses from leaders (we refer to it as "doing the right thing" in Table 5). We note possible implications for the co-occurrence of these dimensions of character definitions below. 
Leaders' influences on character development. We applied six main codes or categories across responses from leaders to the question of if and how they influenced character development in the Scouts they serve (Table 6 provides a description of codes and examples).

\section{Table 6}

Codes and Examples of Adult Volunteer Open-ended Responses about Character Development. Leaders Responded to the Prompt: "Do you try to influence the development of character in youth? Please explain?"

\begin{tabular}{|l|l|c|}
\hline Code & Example & $\begin{array}{l}\text { N (\% of total } \\
\text { respondents) }\end{array}$ \\
\hline $\begin{array}{l}\text { Teaching character } \\
\text { attributes }\end{array}$ & $\begin{array}{l}\text { "I always incorporate the scout law in my den } \\
\text { meetings. This is a high priority to me and the boys } \\
\text { must learn and abide by them." }\end{array}$ & $51(59 \%)$ \\
\hline Leading by example & $\begin{array}{l}\text { "Yes. I strongly believe that one must lead by example } \\
\text { and I try to do that in my daily life both inside and } \\
\text { outside of my scouting units." }\end{array}$ & $36(41 \%)$ \\
\hline $\begin{array}{l}\text { Providing opportunities } \\
\text { for learning character } \\
\text { through active } \\
\text { participation }\end{array}$ & $\begin{array}{l}\text { "Yes. We encourage all the youth to be denners and } \\
\text { practice leading as well as respecting others, youths } \\
\text { and adults." }\end{array}$ & $12(14 \%)$ \\
\hline $\begin{array}{l}\text { Recognizing/acknowled } \\
\text { ging Scout } \\
\text { demonstrations of } \\
\text { character }\end{array}$ & $\begin{array}{l}\text { "I always try to enforce the Good traits \& downplay the } \\
\text { Bad or use the Bad as a leaning tool." }\end{array}$ & $8(10 \%)$ \\
\hline $\begin{array}{l}\text { Working with Scouts to } \\
\text { solve } \\
\text { problems/overcome } \\
\text { challenges }\end{array}$ & $\begin{array}{l}\text { "...In some instances, talking with the youth about a } \\
\text { situation they may find themselves in and asking } \\
\text { questions so they can figure out the answer on their } \\
\text { own. }\end{array}$ & $5(6 \%)$ \\
\hline \begin{tabular}{l} 
No \\
\hline
\end{tabular} & & $2(2 \%)$ \\
\hline
\end{tabular}

Analogous to the coding of leaders' character definitions, we frequently coded individual responses to this question with two or more codes in order to capture the full content of leaders' responses. The code we most frequently applied to responses was "teaching character attributes." We applied this code to responses wherein leaders described using specific strategies to teach character-related values and behaviors to Scouts as the main way in which they influence their character development.

Specifically, 51 leaders described conscientiously using particular strategies to teach aspects of character to Scouts. Many of these leaders also referenced using the specific BSA curriculum as the main way in which they try to influence character. For example, one leader noted: "We try to teach the core values of scouting and good citizenship through discussions, examples, and activities. "Another leader explained: "We use the character connections to talk about what we learn by completing the activities and how it applies to how we live our daily lives." Another leader shared: "We are working to teach them the principles of the Boy Scout Law and how to 
be a good citizen. We expand their horizons by working on things and doing things that they would never otherwise do at home or in front of a TV or computer game." In this excerpt, we also identified that this leader believed that he or she influenced character development through actively engaging youth in Scout-specific activities, or "things that they would never otherwise do."

Additional codes applied to leaders' responses about influencing character development were: leading by example, praising Scouts' demonstrations of character, and assisting with problem solving. Several leaders also explained that they did not specifically try to influence character development in Scouts. However, these leaders did not describe further whether this was because they did not adhere to the character values in Scouting, or if it was because they did not consider themselves to be influential in the development of the Scouts with whom they interacted.

Taken together, the majority of leaders' descriptions of if and how they influenced character development in Scouts suggests that they understood themselves to be vital to the process of character development in Scouting. Moreover, these findings suggest that leaders supported the character-based curriculum of Scouting and that many drew from it directly as they tried to influence the activities and daily development of the Scouts with whom they interacted. In addition, just as leaders frequently defined character as a feature of behaviors and beliefs, so, too, did they describe what actions they took to influence character development in terms of facilitating concrete activities for Scouts that are based on developing character, and ensuring their own behaviors as volunteer leaders reflected their character-based values. This fusion of behaviors and beliefs in leaders' descriptions of how they try to influence character development is exemplified in this leader's description of what he or she does to influence character in Scouts:

...When I'm in front of the boys discussing something, I ask a lot of questions. I will then craft the conversation/lesson around their answers, and around the follow-up questions that naturally arise. This is to show ways to work through challenges or problems, rather than settling or giving up. Looking for alternate answers, or better yet, finding different pathways to the same answer improves decision-making abilities, and hopefully illustrates the need for being mentally aware and awake. I try to model using Honesty as a foundation for all else; using an honest outlook about yourself and then extending that to an honest outlook towards those around you.

Although not every leader stated as clearly the learning objectives behind the teaching activities (and other behaviors) that he or she facilitated for Scouts, many espoused a similar commitment to engaging youth in meaningful character-based activities and to trying to model their own character values for Scouts.

\section{Discussion}

The CAMP project was launched in order to understand the role of Scouting in character development and to assess if innovations in Scouting programs were associated with such development. This study is one of the first longitudinal and mixed-method examinations of character development in a character-based youth development program context. Although prior research has been conducted in the context of Scouting programs, this past research was largely non-developmental. It did not elucidate the processes through which components of the BSA program (e.g., leader-Scout interactions, BSA curriculum, and BSA activities, such as 
camping and outdoor recreation) influenced character development or other positive outcomes among Scouts.

In the present article, we reported findings from the initial wave of data collection of the CAMP study. This initial work was aimed at establishing the key foundations of the study-that is, that youth who begin Cub Scouts are not already different than non-Scout youth, and that the BSA program and its new innovations are being implemented as designed in Scouting programs. Through such baseline assessments careful selection of comparison youth not participating in Scouting, and use of propensity score matching as a statistical means to control for endogeneity, we believed we could provide this foundation. Accordingly, in order to accomplish these aims, we asked three questions:

1. What features of character do youth possess at their entry into the Cub Scout program, and do these attributes differ from those of youth who are not participating in Cub Scouts?;

2. How do QUEs and pack leaders describe their roles and experiences in Cub Scouting, and in regard to the innovation of the QUE program in particular?; and

3. Are leaders' descriptions of their roles and experiences commensurate with BSA program goals in regard to character development; that is, in regard to putting youth on a life path of honor and duty?

As reported above, results in response to Question 1 were that, once propensity scores were used as a covariate in comparison analyses of ACCEA data from Scouts and non-Scouts, there was no difference in character attributes between youth enrolled in Cub Scouts and youth not enrolled in Cub Scouts. Both Scouts and non-Scouts had high and comparable levels of all of the character attributes assessed on the ACCEA measure. In the non-propensity score analyses, there was one difference, in reverence; this finding may have occurred because many of the youth in our comparison group were enrolled in parochial schools. Although non-Scouts were found to have significantly higher levels of reverence compared to Scouts in the initial analysis, this difference disappeared when propensity score analysis was used. This finding suggests that, when controls for endogeneity are introduced, Scouts and non-Scouts may be treated as having comparable levels of character. As such, through subsequent, longitudinal assessments, the CAMP study can gauge if experiences in Scout programs (indexed by content, intensity, and duration of these experiences) are associated with differences in character development in ways not evident in non-Scout youth.

In response to Question 2, qualitative data from QUE interviews confirmed that QUEs' understandings of their positions in Scouting, and in relation to pack leaders and Scouts, was generally commensurate with the description of the QUE position in BSA programs. Most importantly, all eight QUEs identified that the main objective of their role was to provide support to pack leaders, which aligns with the main intentions of the QUE program developed by the COL council. All eight QUEs also identified their roles in BSA programs as focused on supporting pack leaders through providing coaching and counseling, as well as assistance with trainings and the recruitment of Scouts. There was variation, however, in the descriptions of the other facets of the QUE position. Several QUEs acknowledged, for example, that as QUEs they were also tasked with helping pack leaders develop calendars, budgets, and fundraising plans, organize popcorn sales, and maintain fidelity to the advancement program within BSA programs (e.g., the Journey to Excellence Program), whereas others could only articulate the general support goal of the QUE position. There was also variation in the connections that QUEs made between aspects of their positions in BSA programs, and how their work may relate to the experiences of Scouts. 
It is likely that these variations in QUE interviews had much to do with individual differences in histories with Scouting. Several QUEs, for example, were newly hired as Scout leaders when the study began, whereas others had been involved in Scouting since they themselves were children. It will, nevertheless, be important to consider their different levels of experience in, and familiarity with, Scouting (and the objectives of the QUE role) as we continue to assess the impact of the QUE program on Scout outcomes at the aggregate level, and as we examine the impact of each QUE on the packs (and Scouts) that receive their support. In addition, it is essential that we recognize other individual characteristics of QUEs, aside from their experiences in Scouting, that may have an impact on their relationships with pack leaders and the ease with which they are able to offer support and guidance to pack leaders throughout the course of the study. In subsequent interviews, we will therefore continue to assess these individual differences and potential strengths, and whether QUEs' reported understandings of, and commitments to, the QUE position are maintained and/or become more prevalent over time, and as QUEs gain more familiarity with the packs under their guidance.

In addition to assessing how QUEs understood their roles at the initial wave of the study, we explored how pack leaders viewed the QUE position and the responsibilities of QUEs in relation to their packs and their Scouts. From the analysis of responses from 41 leaders who reported being served by a QUE, it became clear that they, too, viewed the QUE position as being created in order to provide them and their packs with support. It will be important to recirculate the pack leader questionnaires at the conclusion of the CAMP study, however, in order to determine if leaders continue to view the QUE program as providing them with support, with enriching experiences as volunteers in BSA programs, and with enhancements of their capacity to deliver an organized and enjoyable program to Scouts.

In response to Question 3, we examined, through an analysis of responses to pack leader questionnaires, how pack leaders defined character and understood their roles in influencing character in Scouts. It was important to gauge leaders' views of character and their role in its development, prior to the assessment of character development longitudinally in subsequent waves, because pack leaders have the most direct contact with Scouts. If we found that leaders did not adopt the BSA character program, then we would be aware a key obstacle in actualizing the hope of BSA personnel; this is, that their programs promote youth character development.

Based on analysis of pack leaders' responses, it was clear, however, that most pack leaders defined character in accordance with the ways in which it is defined within BSA programs. Pack leaders defined character as one's beliefs and values, and/or as influencing (and reflected in) one's actions and interactions with other people and settings (or as some combination thereof). Some leaders defined character in more grounded terms, and even went so far as to list the attributes of character described in the Scout Oath, in the BSA curriculum and, thus, in the ACCEA measure, as the way in which they themselves defined character.

Pack leaders' definitions of character by and large supported BSA program goals reflecting that pack leaders will influence character outcomes in Scouts through delivering and implementing the values-based curriculum and activities (that are at the core of BSA programs). Pack leaders' specific definitions of character also frequently reflected some of the complexity with which character is defined in the youth development literature (see Sokol, et al., 2010, for example), as a blending of both internal and external processes. From the perspectives of leaders in Scouting, character is one's beliefs, values, and moral compass, as well as how one acts "when no one is looking." The complexity in the definitions provided by pack leaders of what 
constitutes character, however, also suggests that youth development scholars and practitioners should further explore how leaders go about influencing such a complicated process within the context of youth development programs.

Accordingly, our longitudinal examination of the process of character development in Scouting, including QUEs' and pack leaders' roles in this process, will attend more explicitly to investigating how they influence the intrinsic components of character (values and belief systems), as well as the extrinsic components they identified (actions toward and interactions with other people and settings). Nevertheless, based on our initial findings from the shortanswer questionnaire, we have information from pack leaders that begins to shed light on this question.

The most common responses provided by pack leaders to the question of how they influenced character were coded as "teaching character attributes." In our analyses of responses, we found that pack leaders were conscientiously trying to use strategies to teach the attributes described in the BSA curriculum to Scouts as they ran pack meetings and facilitated Scout activities. Pack leaders also frequently described "leading by example" as the way in which they tried to influence character in Scouts. Some of the examples leaders provided of how they "led by example" focused on demonstrating the character values they sought to foster in Scouts, whereas others focused more on extrinsic processes or behaviors (e.g., "I try to act the way I want them to act"). Other facets of the pack leader role that were mentioned in leaders' descriptions of how they influenced character included facilitating their active participation in character-promoting and problem solving activities, as well as publicly recognizing and acknowledging when Scouts demonstrated character attributes that were in line with the Scouting context.

In sum, we found that leaders' descriptions of how they intend to influence character development in Scouts generally reflect the ways in which they define character. In addition, the responses provided by leaders to the questions about character development were consistent with the Scouting context. Leaders' descriptions of the particular behaviors they tried to influence in Scouts were commensurate with those behaviors targeted by BSA programs (e.g., contribution). Leaders' commitments to developing "good citizens" who are contributing members of their peer groups, Scout packs, and the larger society, through serving as role models to Scouts, was clear from analyzing leaders' responses to the short- answer questionnaire. In short, the leaders believed that they were helping to launch youth on a life path marked by honorable living and duty.

It is important to note, however, that pack leaders' descriptions of how they aimed to influence character development did not include a focus on trying to keep youth in Scouting for longer periods of time, although retention was a clear goal articulated by the QUEs in this study. From the pack leaders' perspectives it seems the strategies that they used to directly engage Scouts in BSA programs, and especially the character-based behaviors and values that are a part of the BSA curriculum, were the main ways in which they aimed to influence positive development and character outcomes. This discrepancy between QUEs' and pack leaders' goals will be considered as we continue to assess character outcomes in Scouts in future waves of the study, as well as the processes through which QUEs influence pack leaders, and how the QUE-pack leader relationship influences Scout outcomes.

Although pack leaders do not mention the goal of retention in their responses of how they tried to influence character in Scouts, they did express their commitment to BSA programs as well as 
their passion for the values-based BSA curriculum. Pack leaders as well expressed trying out many strategies to engage Scouts in the curriculum and activities, and articulated the ways in which they tried to model Scout values. It is possible that, by focusing on delivering a more effective and enjoyable character-development program to Scouts, while QUEs focus on technical components of BSA programs (e.g., recruitment and retention of Scouts), pack leaders are placing their energy in the right place, and that the QUE program is working out as intended. Whether this potential balance is maintained throughout the course of the CAMP study, and with positive influences on Scout outcomes, will be assessed in future waves.

\section{Conclusions}

There are, of course, several limitations of the present research, ones pertaining to sampling (e.g., the participants were volunteers), measurement (e.g., our index of character pertained to the attributes associated with BSA), and analysis (e.g., the present data are all cross-sectional). Although these data provide important information about individual variables (regarding character attributes) and contextual variables (the roles of the QUEs and pack leaders in regard to youth character), only longitudinal data (to-be-generated in the subsequent waves of the CAMP study) will suffice in testing the RDS ideas about individual-context bidirectional relations that are integral to the RDS/PYD model framing this research (e.g., Lerner, et al., in press; Overton, in press).

Indeed, as this study continues through several waves of testing, we will assess character development within historical time and, as such, within a period in which the programs of Boy Scouts of America are evolving in the context of social issues, involving inclusion and social justice. As such, our future reports from this study will elucidate the importance of historical time and place (Elder, Shanahan, \& Jennings, in press) on the context of a youth development program for the positive development of the youth it serves.

In sum, the evidence gathered during this initial phase of a larger longitudinal study supported the descriptions of character in Scouting, and of the roles of QUEs and adult leaders, described by BSA programs. In addition, through qualitative analyses of pack leader responses in particular, we have generated understandings of how leaders in a youth development program define character and character development. We have also confirmed that pack leaders' views of character fit well within the context of BSA programs; this is an important corroboration given that pack leaders are charged with delivering BSA curriculum and activities to Scouts.

Moreover, through qualitative and quantitative data collection and analyses from the initial wave of the study, we were able to describe what character attributes may look like in Scouts participating in the CAMP study at baseline. Furthermore, we have illustrated that Scouts and non-Scouts have generally similar levels of character attributes, in particular when matched through propensity score analyses. This comparability allows us to make useful assessments between the Scouts and the non-Scouts as we move into subsequent stages of data collection and longitudinal analysis. As such, this project has the potential to provide novel information about contributions to character development of a major youth development program in the United States.

Acknowledgement: The first and second authors contributed equally to the manuscript. This research was supported by a grant to Richard M. Lerner from the John Templeton Foundation. 


\section{References}

Benson, P L., Scales, P.C., \& Syvertsen, A.K. (2011). The contribution of the developmental assets framework to positive youth development theory and practice. In R.M. Lerner, J.V. Lerner, \& J.B. Benson (Eds.). Advances in Child Development and Behavior, 41, 197-230.

Census. (2000). American Community Survey. From http://www.census.gov/main/www/cen2000.html

Census. (2010). American Community Survey. From

http://www.census.gov/acs/www/about the survey/american community survey and $2010 \mathrm{c}$ ensus/

Damon, W. (2004). What is positive youth development? The Annals of the American Academy, 591, 13-24.

Eccles, J.S., \& Gootman, J.A. (Eds.). (2002). Community programs to promote youth development. National Academies Press.

Elder, G.H., Jr., Shanahan, M.J., \& Jennings, J.A. (In press). Human development in time and place. In M.H. Bornstein and T. Leventhal (Eds.), Handbook child psychology and science (7th ed.), Volume 4: Ecological settings and processes in developmental systems. Editor-in-chief: R.M. Lerner. Hoboken, N.J.: Wiley.

ESRI. (2012). Tapestry segmentation reference guide. Redlands (CA): Environmental Systems Research Institute. http://www.esri.com/library/brochures/pdfs/tapestry-segmentation.pdf

Gestsdóttir, S., \& Lerner, R.M. (2008). Positive development in adolescence: The development and role of intentional self regulation. Human Development, 51, 202-224.

Harder, V.S., Stuart, E.A., \& Anthony, J.C. (2010). Propensity score techniques and the assessment of measured covariate balance to test causal associations in psychological research. Psychological methods, 15(3), 234.

Harris Interactive (2003). Volunteer outcomes study. Irving, TX: Boy Scouts of America National Office.

Harter, S. (1982). The perceived competence scale for children. Child Development, 53(1), 8797.

Harter, S. (1983). Developmental perspectives on the self-system. In P.H. Mussen (Ed.), Handbook of child psychology: Social and personality development ( $4^{\text {th }}$ ed., pp. 275-385). New York, NY: Wiley.

Heckman, J.J., Ichimura, H., \& Todd, P.E. (1997). Matching as an econometric evaluation estimator: Evidence from evaluating a job training programme. The Review of Economic Studies, 64(4), 605-654. 
Heckman, J.J., Ichimura, H., \& Todd, P. (1998). Matching as an econometric evaluation estimator. The Review of Economic Studies, 65(2), 261-294.

Hsieh, H., \& Shannon, S.E. (2005). Three approaches to qualitative content analysis. Qualitative Health Research, 15(9), 1277-1288.

Jang, S.J., Johnson, B.R., \& Kim, Y. (2012). Eagle Scouts: Merit beyond the badge. Institute for Studies of Religion, Baylor University. Retrieved from http://www.baylorisr.org/wpcontent/uploads/Boy-Scouts-Report.pdf

Lapsley, D.K., \& Narvaez, D. (2006). Character education. In A. Renninger \& I. Siegel (Volume Eds.), Handbook of child psychology (Vol 4, W. Damon \& R.M. Lerner, Series Eds.) (pp.248296). New York, NY: Wiley.

Larson, R.W. (2000). Toward a psychology of positive youth development. American Psychologist, 55(1), 170-183.

Lerner, R.M. (2004). Liberty: Thriving and civic engagement among American youth. Thousand Oaks, CA: Sage.

Lerner, R.M., \& Callina, K.S. (in press). The study of character development: Towards tests of a relational developmental systems model. Human Development.

Lerner, R.M., Lerner, J.V., Almerigi, J., Theokas, C., Phelps, E., Gestsdottir, \& von Eye, A. (2005). Positive youth development, participation in community youth development programs, and community contributions of fifth grade adolescents: Findings from the first wave of the 4-H Study of Positive Youth Development. Journal of Early Adolescence, 25, 17-71.

Lerner, R.M., Lerner, J.V., Bowers, E.P., \& Geldhof, G.J. (In press). Positive youth development and relational developmental systems. In W.F. Overton \& P.C. Molenaar (Eds.), Theory and method. Volume 1 of the Handbook of child psychology and developmental science (7th ed.). Editor-in-chief: R.M. Lerner. Hoboken, NJ: Wiley.

Lickona, T., \& Davidson, M. (2005). Smart and good high schools: Integrating excellence and ethics for success in school, work, and beyond. Cortland, NY: Center for the 4th and 5th Rs (Respect and Responsibility). Washington, D.C.: Character Education Partnership.

Louis Harris \& Associates. (1998). A year in the life of a Cub Scout...Boy Scout...Venturer: Strengthening youth, families, and neighborhoods. New York, NY: Louis Harris \& Associates, Inc. Retrieved from http://www.scouting.org/FILESTORE/marketing/pdf/02-303.pdf/

Mahoney, J.L., Vandell, D.L., Simkins, S., \& Zarrett, N. (2009). Adolescent out-of-school activities. In R.M. Lerner \& L. Steinberg (Eds.), Handbook of adolescent psychology: Vol. 2. Contextual influences on adolescent development (3rd ed., pp. 228-269). Hoboken, NJ: Wiley.

McGrath, R. (2014). Scale- and item-level factor analyses of the VIA inventory of strengths. Assessment, 21(1), 4-14.

Overton, W.F. (2013). A new paradigm for developmental science: Relationism and relationaldevelopmental systems. Applied Developmental Science, 17(2), 94-107. 
Overton, W.F. (In press). Process and relational developmental systems. In W.F. Overton \& P.C.M. Molenaar (Eds.), Theory and method. Volume 1 of the Handbook of child psychology and developmental science (7th ed.). Editor-in-chief: R.M. Lerner. Hoboken, NJ: Wiley.

Peterson, C., \& Seligman, M.E.P. (2004). Character strengths and virtues: $A$ handbook and classification. New York, NY: Oxford University Press.

Polson, E.C., Kim, Y.I., Jang, S.J., Johnson, B.R., \& Smith, B. (2013). Being prepared and staying connected: Scouting's influence on social capital and community involvement. Social Science Quarterly, 94, 758-776.

Rosenbaum, P.R., \& Rubin, D.B. (1985). Constructing a control group using multivariate matched sampling methods that incorporate the propensity score. The American Statistician, 39(1), 33-38.

Saldaña, J. (2012). The coding manual for qualitative researchers. Thousand Oaks, CA: Sage.

Sandelowski, M. (2001). Real qualitative researchers do not count: The use of numbers in qualitative research. Research in Nursing \& Health, 24, 230-240.

Seider, S. (2012). Character compass: How powerful school culture can point students toward success. Cambridge, MA: Harvard Education Press.

Schmid, K.L., \& Lopez, S. (2011). Positive pathways to adulthood: The role of hope in adolescents' constructions of their futures. In R.M. Lerner, J.V. Lerner, \& J.B. Benson (Eds.), Advances in child development and behavior: Positive youth development (Vol. 41, pp. 72-89). London, England: Academic Press.

Sherrod, L.R., Torney-Purta, J., \& Flanagan, C.A. (2010). Handbook of research on civic engagement in youth. Hoboken, NJ: John Wiley \& Sons.

Shields, D.L. (2011). Character as the aim of education. Phi Delta Kappan, 92(8), 48-53.

Sokol, B.W., Hammond, S.I., \& Berkowitz, M.W. (2010). The developmental contours of character. In T. Lovat, R. Toomey, \& N. Clement (Eds.). International Research Handbook on values education and student wellbeing (pp. 579-603). New York, NY: Springer.

Vandell, D.L., Larson, R.W., Mahoney, J.L., \& Watts, T.W. (in press). Children's organized activities. In M.H. Bornstein, T. Leventhal, \& R.M. Lerner (Eds.), Handbook of child psychology and developmental science, Vol 4: Ecological settings and processes in developmental systems ( $7^{\text {th }}$ ed). New York, NY: Wiley.

Wang, J., Hilliard, L.J., Hershberg, R.M., Bowers, E.P., Chase, P.A., Champine, R.B.,... Lerner, R.M. (2014). Character in childhood and early adolescence: Models and measurement. Unpublished manuscript. Institute for Applied Research in Youth Development: Medford, MA: Tufts University.

(C) Copyright of Journal of Youth Development $~$ Bridging Research and Practice. Content may not be copied or emailed to multiple sites or posted to a listserv without copyright holder's express written permission. Contact Editor at: patricia.dawson@oregonstate.edu for details. However, users may print, download or email articles for individual use.

ISSN 2325-4009 (Print); ISSN 2325-4017 (Online) 